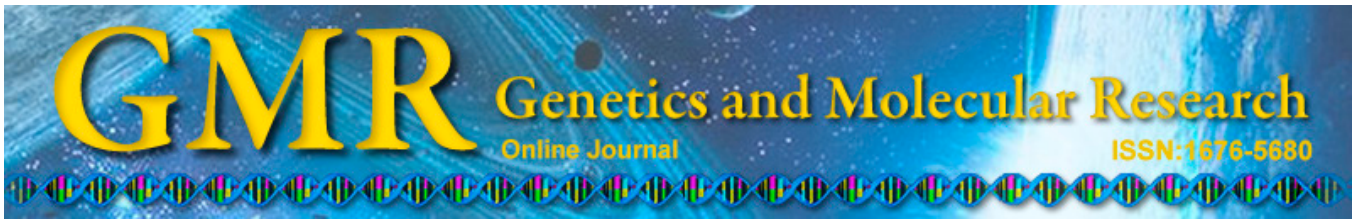

\title{
Expression and clinical significance of ADAM17 protein in esophageal squamous cell carcinoma
}

\author{
H.B. Liu, Y. Zhu, Q.C. Yang, Y. Shen, X.J. Zhang and H. Chen \\ Department of Pathology First People's Hospital of Nantong City, \\ Jiangsu Province, China \\ Corresponding author: H.B. Liu \\ E-mail: liuhongbin_1hb@126.com
}

Genet. Mol. Res. 14 (2): 4391-4398 (2015)

Received June 4, 2014

Accepted October 27, 2014

Published April 30, 2015

DOI http://dx.doi.org/10.4238/2015.April.30.12

ABSTRACT. We examined disintegrin and metalloproteinase 17 (ADAM17) protein expression in esophageal squamous cell carcinoma and its clinical and pathological correlated factors. Western blotting and immunohistochemistry were used to detect ADAM17 protein expression in esophageal squamous cell carcinoma and the corresponding normal esophageal mucosa in 50 cases. ADAM17 protein expression in 50 cases with esophageal squamous cells was $0.887 \pm 0.174$; the positive expression rate was $66 \%(33 / 50)$. ADAM17 protein expression in corresponding normal esophageal mucosa was $0.273 \pm 0.081$; the positive expression rate was $6 \%(3 / 50)$. Expression in esophageal squamous cell carcinoma was significantly higher than that in the normal esophageal group $(\mathrm{P}<0.01)$. Esophageal squamous cell ADAM17 protein expression and the positive rate were correlated with lymph node metastasis and TNM stage $(\mathrm{P}<0.05)$, but not correlated with gender, age, and histological grade $(\mathrm{P}>0.05)$. ADAM17 protein was highly expressed in esophageal squamous cell carcinoma. This protein may play an important role in the incidence, invasion, and 
metastasis of esophageal cancer and is valuable for the prognosis of patients with esophageal cancer.

Key words: Esophageal cancer; Disintegrin-metalloproteinase 17; Immunoblotting

\section{INTRODUCTION}

Esophageal cancer is the most common malignancy of the digestive system and has a 5 -year survival rate of less than $10 \%$. The main reason for the poor prognosis is that esophageal cancer has a high invasive intensity to surrounding tissue and is prone to lymph node metastasis. Although the molecular markers of esophageal cancer have been examined in many studies, the mechanism of invasion and metastasis of esophageal cancer remains unclear. Disintegrin metalloproteinase 17 (ADAM17) is also known as a tumor necrosis factor- $\alpha$-converting enzyme. Studies have shown that ADAM17 releases important biological ligands such as tumor necrosis factor- $\alpha$ and transforming growth factor- $\alpha$, and that it is involved in tumor formation and progression (Blobel, 2002). In this study, we used Western blotting and immunohistochemistry methods to examine ADAM17 protein expression in esophageal squamous cell carcinoma to determine its clinical pathological significance and its role in the development of esophageal squamous cell carcinoma.

\section{MATERIAL AND METHODS}

\section{Materials}

From 2006 to 2010, we collected 50 cases of esophageal carcinoma specimens and adjacent normal esophageal mucosa from the same set of patients in the Pathology Department of Nantong First People's Hospital. Specimens were fresh tissues with no necrosis that were frozen in liquid nitrogen within $30 \mathrm{~min}$ and transferred quickly to $-80^{\circ} \mathrm{C}$. None of the patients had received pre-operative radiotherapy and chemotherapy, and the cases were diagnosed using histopathological examination. There were 33 males and 17 females, with ages of 45-77 years and a median age of 61 years. The esophageal cancer histological grade of the 50 cases was as follows: 10 cases with grade I, 26 cases with grade II, and 14 cases with grade III. TNM staging was as follows: 5 cases with stage I, 24 cases with stage II, 15 cases with stage III, and 6 cases with stage IV.

\section{METHODS}

\section{Western blotting assay of ADAM17 protein}

Esophageal cancer specimens and their paired adjacent normal esophageal mucosa were washed with cold phosphate-buffered saline 3 times, and the blood on the tissue blocks was washed away. Liquid nitrogen was quickly added to make the samples into powder; protein lysates were added on ice for $4 \mathrm{~h}$ or to the lysates overnight at $4^{\circ} \mathrm{C}$. Centrifugation $(12,000$ g) was performed for $30 \mathrm{~min}$ at $4^{\circ} \mathrm{C}$, and supernatants were collected to detect protein content using an ultraviolet spectrophotometer. A $40-\mu \mathrm{g}$ protein sample was removed and analyzed 
by sodium dodecyl sulfate-polyacrylamide gel electrophoresis with a $4.0 \%$ stacking gel and $7.5 \%$ separating gel. The gel was run at $80 \mathrm{~V}$ for the stacking gel and then switched to $100 \mathrm{~V}$ until the samples were added onto the gel. After electrophoresis, wet electrical transfer was performed. Samples in the gel were transferred to a polyvinylidene fluoride membrane (Millipore Corporation, Billerica, MA, USA) and then incubated for $2 \mathrm{~h}$ with Tris-buffered saline with Tween 20 buffer containing 10\% skim milk at room temperature. The rabbit anti-human ADAM17 monoclonal antibody and $\beta$-actin antibody were used (1:1000 dilution). After incubation for $1 \mathrm{~h}$ at room temperature and then at $4{ }^{\circ} \mathrm{C}$ overnight, Tris-buffered saline with Tween 20 was used to wash the membrane for $5 \mathrm{~min}, 5$ times. The sealed dilute solution was added to dilute mouse anti-human secondary antibody at room temperature for $1 \mathrm{~h}$; and Tris-buffered saline Tween 20 buffer was used to wash the membrane for 15 min 4 times. Finally, electrochemiluminescence detection, development, and fixation were performed.

\section{ADAM17 protein detection using immunohistochemistry Streptavidin-peroxidase (SP) method}

All specimens were fixed in 10\% neutral formalin solution, paraffin-embedded, and sliced into 4- $\mu \mathrm{m}$ sections. Following hematoxylin and eosin staining and immunohistochemical SP staining, primary anti-rabbit anti-human monoclonal antibody (1:100 dilution) for ADAM17 was added (Beijing Zhongshan Golden Bridge Biotechnology Co. Ltd., Beijing, China).

\section{Analysis methods}

\section{Western blotting detection}

Bands observed at $110 \mathrm{kDa}$, were identified as corresponding to the ADAM17 protein, and $\beta$-actin (molecular weight of $42 \mathrm{kDa}$ ) was used as the internal control. The Eagle eye II image analysis system (Agilent Technologies Inc, California, USA) was used for electrophoretic band scanning. ADAM17 protein is presented as the ratio of the ADAM17 optical density to the $\beta$-actin optical density in the same tube.

\section{Immunohistochemistry}

Based on a previous study (Le Gall et al., 2009), the 4 grades according to the percentage of positive cells were as follows: 0 : no positive cell; 1 point: $<30 \%$ positive cells; 2 points: $>30-70 \%$ positive cells; and 3 points: $>70 \%$ positive cells. The 4 grades according to the staining intensity were as follows: 0 : no positive cell; 1 point: positive cells were stained pale yellow; 2 points: positive cells were stained yellow; 3 points: positive cells were stained brown. These scores were combined and evaluated as follows: 0 was negative (-), 1-2 points were slightly positive $(+), 3-4$ points were moderately positive $(++)$, and 5-6 points were strongly positive $(+++)$. We classified $(-)$ and $(+)$ as the negative group and $(++)$ and $(+++)$ as the positive group.

\section{Statistical analysis}

The Stata 7.0 statistical package was used (StataCorp LP, College Station, TX, USA). 
ADAM17 protein expression detected by Western blotting is reported as means \pm standard deviation and the Student $t$-test was used to compare groups. The chi-square test was used to compare rates. The significance level was set as $\alpha=0.05$.

\section{RESULTS}

\section{ADAM17 protein expression in esophageal squamous cell carcinoma}

Western blotting analysis showed that ADAM17 protein was expressed to varying levels in esophageal squamous cell carcinoma and adjacent normal esophageal mucosa (Figure 1). ADAM17 protein expression in esophageal squamous cell carcinoma $(0.887$ $\pm 0.174)$ was significantly higher than that in the normal esophageal mucosa $(0.273 \pm$ $0.081)$; the difference was statistically significant $(P<0.01$, Table 1$)$. Immunohistochemical detection showed that ADAM17 expression was in brown or brownish-yellow granules that appeared in the cell cytoplasm in esophageal cancer (Figures 2 and 3). Of the 50 cases of esophageal cancer, 33 cases showed positive ADAM17 protein expression, with a positive rate at $66 \%$; the positive rate in corresponding normal tissues was $6 \%$; the difference was statistically significant $(\mathrm{P}<0.01)$.

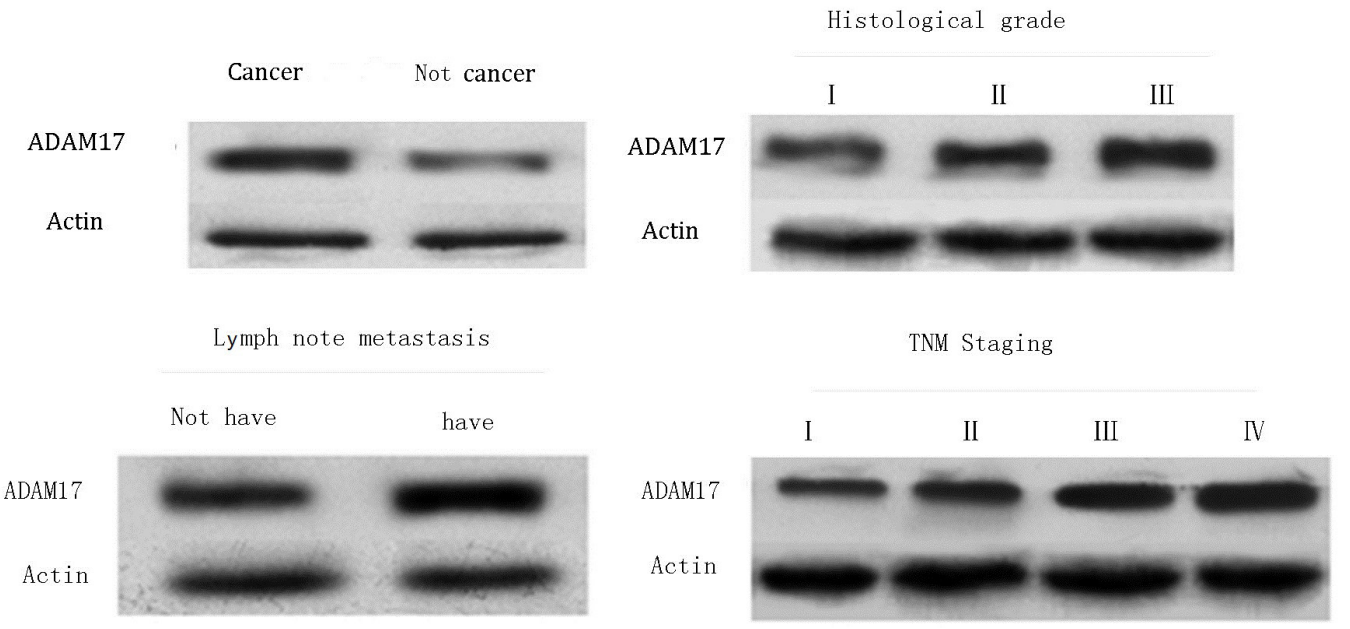

Figure 1. Western blotting electrophoresis of ADAM17 protein in different esophageal squamous carcinoma cells and normal esophageal tissues.

Table 1. ADAM17 protein expression in esophageal squamous cell carcinoma and normal esophageal tissues.

\begin{tabular}{|c|c|c|c|c|c|c|c|}
\hline \multirow[b]{2}{*}{ Group } & \multirow[b]{2}{*}{ No. of cases } & \multicolumn{2}{|c|}{ Western blotting } & \multicolumn{4}{|c|}{ SP staining } \\
\hline & & Means \pm SD & $\mathrm{P}$ & $-(\mathrm{N})$ & $+(\mathrm{N})$ & Positive rate & $\mathrm{P}$ \\
\hline Normal esophageal & 50 & $0.273 \pm 0.081$ & 0.000 & 47 & 3 & $6 \%$ & 0.000 \\
\hline Esophageal squamous cell carcinoma & 50 & $0.887 \pm 0.174$ & & 17 & 33 & $66 \%$ & \\
\hline
\end{tabular}




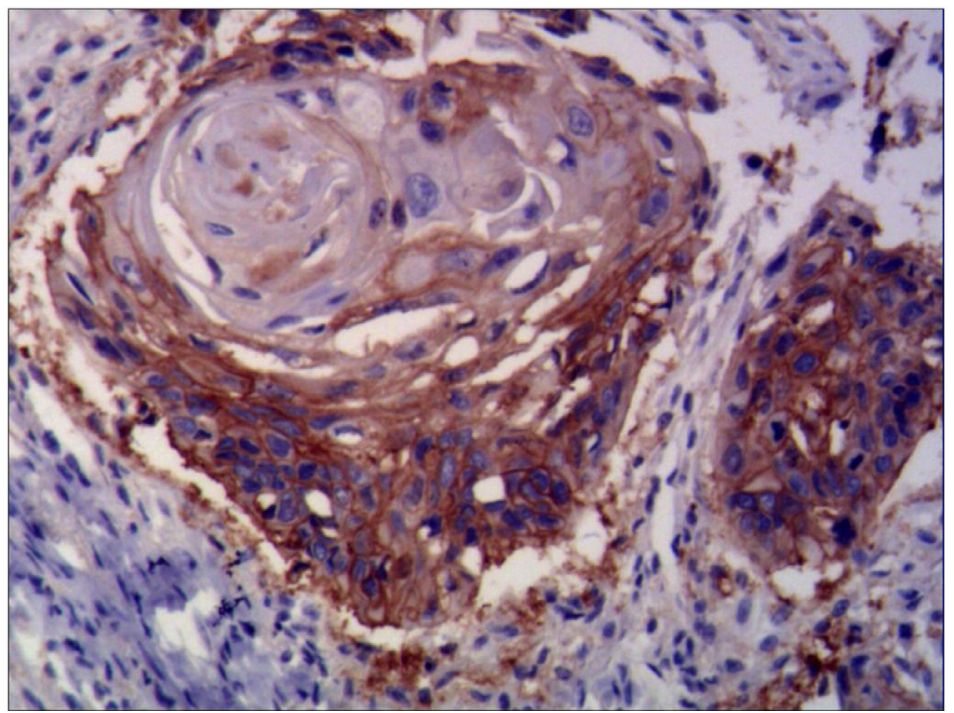

Figure 2. ADAM17 expression in esophageal cancer cells was located in the cytoplasm in which brown granules appeared, positive $(++)$, SP 100X.

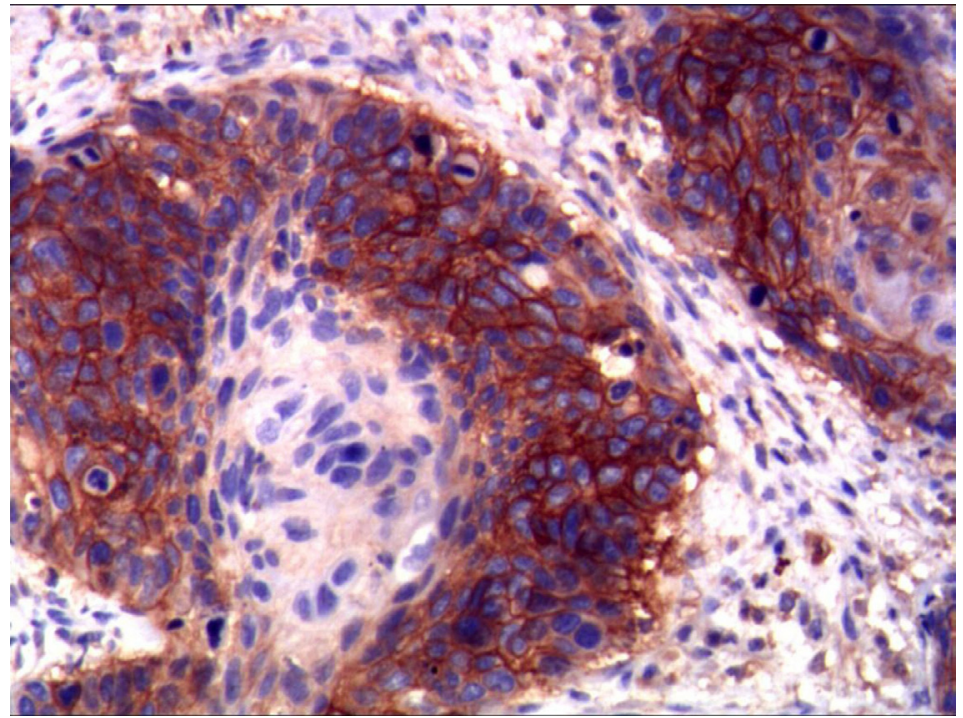

Figure 3. ADAM17 expression in esophageal cancer cells was located in the cytoplasm in which brown granules appeared, positive $(+++)$, SP 100X.

\section{Comparison of ADAM17 protein expression and esophageal squamous cell carcinoma clinicopathological factors}

Western blotting and immunohistochemistry results showed that ADAM17 protein expression and the positive rate in the lymph node metastasis group were significantly higher than those in the lymph node-negative group $(\mathrm{P}<0.05)$ (Table 2). For TNM staging, ADAM17 
protein expression and the positive rate in patients in stages I and II were significantly different from those in patients in stages III and IV $(\mathrm{P}<0.05)$. ADAM17 protein expression levels and positive rates increased with esophageal histology I, II, and III stages; however, the difference was not statistically significant $(\mathrm{P}>0.05)$. ADAM17 protein expression levels and positive rates showed no significant difference with other clinicopathological factors such as gender and age $(\mathrm{P}>0.05)$.

Table 2. ADAM17 protein expression of esophageal carcinoma and its association with clinical pathological factors.

\begin{tabular}{|c|c|c|c|c|c|c|c|}
\hline \multirow[b]{2}{*}{ Group } & \multirow[b]{2}{*}{ No. of cases } & \multicolumn{2}{|c|}{ Western blotting } & \multicolumn{4}{|c|}{ SP staining } \\
\hline & & Means \pm SD & $\mathrm{P}$ & - & + & Positive rate & $\mathrm{P}$ \\
\hline \multicolumn{3}{|l|}{ Gender } & \multirow[t]{3}{*}{0.209} & & & & \multirow[t]{3}{*}{0.890} \\
\hline Male & 33 & $0.892 \pm 0.172$ & & 10 & 23 & $69.70 \%$ & \\
\hline Female & 17 & $0.821 \pm 0.213$ & & 7 & 10 & $58.82 \%$ & \\
\hline \multicolumn{2}{|l|}{ Age (years) } & & \multirow[t]{3}{*}{0.539} & & & & \multirow[t]{3}{*}{0.480} \\
\hline$\leq 60$ & 23 & $0.862 \pm 0.314$ & & 9 & 14 & $60.87 \%$ & \\
\hline$>60$ & 27 & $0.904 \pm 0.149$ & & 8 & 19 & $70.39 \%$ & \\
\hline \multicolumn{2}{|c|}{ Histological grading } & & \multirow{4}{*}{0.148} & & & & \multirow{4}{*}{0.231} \\
\hline I & 10 & $0.832 \pm 0.272$ & & 7 & 3 & $30.00 \%$ & \\
\hline II & 26 & $0.903 \pm 0.138$ & & 14 & 11 & $44.00 \%$ & \\
\hline III & 14 & $1.081 \pm 0.173$ & & 5 & 9 & $64.29 \%$ & \\
\hline \multicolumn{2}{|c|}{ Lymph node metastasis } & & \multirow[t]{3}{*}{0.007} & & & & \multirow[t]{3}{*}{0.021} \\
\hline No & 30 & $0.827 \pm 0.274$ & & 14 & 16 & $53.33 \%$ & \\
\hline Yes & 20 & $1.017 \pm 0.144$ & & 3 & 17 & $85.00 \%$ & \\
\hline \multicolumn{2}{|l|}{ TNM stage } & & \multirow[t]{3}{*}{0.001} & & & & \multirow[t]{3}{*}{0.036} \\
\hline $\mathrm{I}+\mathrm{II}$ & 29 & $0.844 \pm 0.131$ & & 13 & 15 & $53.57 \%$ & \\
\hline III + IV & 21 & $1.021 \pm 0.217$ & & 4 & 18 & $81.82 \%$ & \\
\hline
\end{tabular}

Because there were fewer cases of TNM stages I and IV, these cases were integrated into the stage II and III groups, respectively.

\section{DISCUSSION}

Cancer metastasis is a multi-step and complex process involving multiple genes, cytokines, receptors, and ligands, as well as other functions participating in cancer development, and metastasis requires proteolytic enzymes to hydrolyze the extracellular domain. ADAM proteins are a secretory protein transmembrane family composed of multi-domains, and their most well known role is the release of biologically important ligands such as tumor necrosis factor- $\alpha$, epidermal growth factor, and transforming growth factor- $\alpha$. Because these ligands are involved in tumor formation and progression, specific ADAM molecules released by these ligands may be involved in the process of tumor malignancy (Blobel, 2002; Le Gall et al., 2009). ADAMl7 is a member of the ADAM superfamily; it is also known as tumor necrosis factor- $\alpha$ converting enzyme. A previous study showed that ADAM-17 is likely a physiological shedding enzyme of tumor necrosis factor- $\alpha$, and that the function of ADAM17 protein may be to hydrolyze and release cell surface precursor protein molecules to alter signal transmission (Le Gall et al., 2009). Recent studies found that ADAM17 was highly expressed in many human tumors and can promote tumor invasion and metastasis. McGowan et al. (2007) studied the association between ADAM17 and breast cancer at the mRNA and protein levels. They found that ADAM17 was positively correlated with the number of lymph node metastases in breast cancer. This demonstrated that ADAM17 was involved in the progression of breast cancer; high expression of ADAM17 increased the invasiveness and the spreading ability of 
breast cancer cells in vitro. ADAM17 can release amphiregulin, transforming growth factor- $\beta$, and other epidermal growth factor receptor (EGFR) ligands, and activated EGFR to enhance the proliferation and motility capacity of lung cancer cells (Baumgart et al., 2010). Ding et al. (2005) found that in hepatocellular carcinoma, ADAM17 mRNA expression was significantly higher than that in the surrounding liver tissue and was closely related to the degree of differentiation of liver cancer, indicating that ADAM17 is related to liver cancer development. Wheeler et al. (2003) confirmed that ADAM17, through its cytokine shedding mechanism, is involved in the formation of metastatic squamous cell carcinoma and may play an important role in tumor invasion and metastasis.

Few studies have examined the role of ADAM17 in esophageal cancer. Sakamoto et al. (2010) used reverse transcription-polymerase chain reaction and Western blotting, and they found that ADAMTS16 protein expression was elevated in esophageal tissue. They also detected ADAMTS16 protein levels in TE5 esophageal cancer cell lines in the medium and showed that by blocking ADAMTS16, cell growth and esophageal cancer invasion of TE5 cells can be inhibited.

We used Western blotting and immunohistochemistry methods to demonstrate that ADAM17 protein expression intensity varied in normal esophageal mucosa and esophageal squamous cell carcinoma. ADAM17 protein expression in esophageal squamous cell carcinoma was significantly higher than that in the normal esophageal mucosa. Our results indicated that ADAM17 overexpression was correlated with the development of esophageal cancer, and thus can be used in the differential diagnosis of benign and malignant lesions in the esophagus.

We also found that ADAM17 protein expression and the positive rate increased with the esophageal histology of I, II, and III stages; however, there was no statistically significant difference. ADAM17 protein expression and positive rate in the lymph node metastasis group were significantly higher than those in the lymph node-negative group. For TNM staging, ADAM17 protein expression and the positive rate in patients in stages I and II were significantly different than those in patients in stages III and IV. Our results showed that ADAMI7 may be associated with uncontrolled proliferation of esophageal cancer cells. ADAM17 participated in the mechanisms of invasion and metastasis and distant dissemination of esophageal cancer cells. The high ADAM17 protein expression may be a marker in the metastasis and prognosis of esophageal squamous cells.

Tanaka et al. (2005) found that ADAM17 can mediate the release of specific EGFR ligands, which can bind to epidermal growth factor and activate the EGFR to cause epithelial hyperplasia disorder and then develop into cancer. A previous study found that ADAMselective protease inhibitors could block the EGFR pathway in tumor cells (Merchant et al., 2008). Currently, the EGFR signaling pathway is a known target of anti-cancer drugs. Some drugs that are already on the market, such as Erbitux ${ }^{\circledR}$, target EGFR. However, the EGFR family uses other receptors in addition to EGFR; it can also receive EGFR ligands and cause downstream signaling. Some patients showed tolerance of clinical drugs that targeted EGFR. In conclusion, using ligands of ADAMs may be useful for treating esophageal squamous cell carcinoma.

\section{ACKNOWLEDGMENTS}

Research supported by the Technology Applied Research Projects Nantong (\#k2010061). 


\section{REFERENCES}

Baumgart A, Seidl S, Vlachou P, Michel L, et al. (2010). ADAM17 regulates epidermal growth factor receptor expression through the activation of Notch 1 in non-small cell lung cancer. Cancer Res. 70: 5368-5378.

Blobel CP (2002). Functional and biochemical characterization of ADAMs and their predicted role in protein ectodomain shedding. Inflamm. Res. 51: 83-84.

Ding X, Yang LY and Huang GW (2005). Expression and significance of ADAM17 mRNA in solitary large hepatocellular carcinoma. Chin. J. Hepatobiliary Surg. 11: 544-546.

Le Gall SM, Bobé P, Reiss K, Horiuchi K, et al. (2009). CP ADAMs 10 and 17 represent differentially regulated components of a general shedding machinery for membrane proteins such as transforming growth factor $\alpha, \mathrm{L}$-selectin, and tumor necrosis factor $\alpha$. Mol. Biol. Cell 20: 1785-1794.

McGowan PM, Ryan BM, Hill AD, McDermott E, et al. (2007). ADAM-17 expression in breast cancer correlates with variables of tumor progression. Clin. Cancer Res. 13: 2335-2343.

Merchant NB, Voskresensky I, Rogers CM, Lafleur B, et al. (2008). TACE/ADAM-17: a component of the epidermal growth factor receptor axis and a promising therapeutic target in colorectal cancer. Clin. Cancer Res. 14: 1182-1191.

Tanaka Y, Miyamoto S, Suzuki SO, Oki E, et al. (2005). Clinical significance of heparin-binding epidermal growth factor and a disintegrin and metal-loproteases 17 expression in human ovarian cancer. Clin. Cancer Res. 11: 4783-4792.

Sakamoto N, Oue N, Noguchi T, Sentani K, et al. (2010). Serial analysis of gene expression of esophageal squamous cell carcinoma: ADAMTS16 is upregulated in esophageal squamous cell carcinoma Cancer Sci. 101: 1038-1044.

Wheeler DL, Ness KJ, Oberley TD and Verma AK (2003). Protein kinase Cepsilon is linked to 12-O-tetrad-ecanoylphorbol13-acetate-induced tumor necrosis factor-alpha ectodomain shedding and the development of metastatic squamous cell carcinoma in protein kinase Cepsilon transgenic mice. Cancer Res. 63: 6547-6555. 